\title{
A comparison of the prevalence of islet autoantibodies in children from two countries with differing incidence of diabetes
}

\author{
D. Marčiulionyte $\dot{1}^{1}$, A.J. K. Williams ${ }^{2}$, P.J. Bingley ${ }^{2}$, B. Urbonaité $\dot{e}^{1}$, E. A.M. Gale ${ }^{2}$ \\ ${ }^{1}$ Laboratory of Paediatric Endocrinology, Kaunas University of Medicine, Institute of Endocrinology, Lithuania \\ ${ }^{2}$ Diabetes and Metabolism, Division of Medicine, University of Bristol, UK
}

\section{Abstract}

Aims/Hypothesis. To examine the prevalence of subclinical islet autoimmunity in children from two countries with a twofold to threefold difference in incidence of childhood Type I (insulin-dependent) diabetes mellitus.

Methods. Sera were collected from 2860 English and 3053 Lithuanian non-diabetic schoolchildren according to the same protocol. Occult diabetes was excluded by blood glucose measurement. Antibodies to GAD and the protein tyrosine phosphatase IA-2 were measured with standardised radiobinding assays in a single laboratory. Islet cell antibodies and insulin autoantibodies were additionally measured in all samples with GAD and/or IA-2 antibody levels above the $97.5^{\text {th }}$ centile of the English schoolchildren. Results. Of Lithuanian schoolchildren $2.7 \%$ had GAD antibodies above the $97.5^{\text {th }}$ centile of the En- glish schoolchildren but only $0.2 \%$ had antibodies to IA-2 above this threshold $(p<0.001)$. Islet cell and/ or insulin autoantibodies above the $97.5^{\text {th }}$ centile were found in 22 Lithuanian and 16 English schoolchildren and the overall prevalence of two or more antibodies on or above the $97.5^{\text {th }}$ centile was similar $[0.7 \%(0.5-1.1)$ vs $0.6 \%(0.4-1.0)]$ in the two cohorts. Conclusion/interpretation. The prevalence of multiple antibody markers was similar in the cohorts from the two populations, despite the two to three-fold difference in incidence of diabetes. The unexpectedly high prevalence of subclinical islet autoimmunity suggests that the incidence of diabetes in Lithuania is likely to increase in the near future. [Diabetologia (2001) 44: 16-21]

Keywords Type I diabetes, islet autoantibodies, GAD antibodies, IA-2 antibodies, insulin autoantibodies, schoolchildren.
There are wide geographical variations in the incidence of childhood Type I (insulin-dependent) diabetes mellitus across Europe with, for example, a tenfold difference between Macedonia and Finland [1]. The onset of Type I diabetes is preceded by a lengthy prodromal period characterized by the appearance of circulating islet autoantibodies [2] and family studies have shown that progression to diabetes is closely

Received: 25 February 2000 and in revised form: 19 June 2000

Corresponding author: Professor E.A.M. Gale, Medical School Unit, Southmead Hospital, Bristol BS10 5NB, UK Abbreviations: IA-2, protein tyrosine phosphatase IA-2; ICA, islet cell antibodies; IAA, insulin autoantibodies; QC, quality control; JDF, Juvenile Diabetes Foundation. linked to the appearance of autoantibodies directed against multiple islet antigens [3,4]. A close correlation between the future incidence of diabetes in a population and the prevalence of islet autoantibodies in the childhood population might therefore be expected. The prevalence of autoantibodies in children could also prove useful as an epidemiological tool to investigate exposure to possible environmental determinants of diabetes.

A number of studies have examined the prevalence of islet cell antibodies (ICA) in healthy schoolchildren and suggest a broad correlation between disease frequency and reported levels of ICA [5-7]. Although attempts have been made to compare studies [8], these comparisons are of limited validity due to lack of standardization of the ICA assay. For exam- 

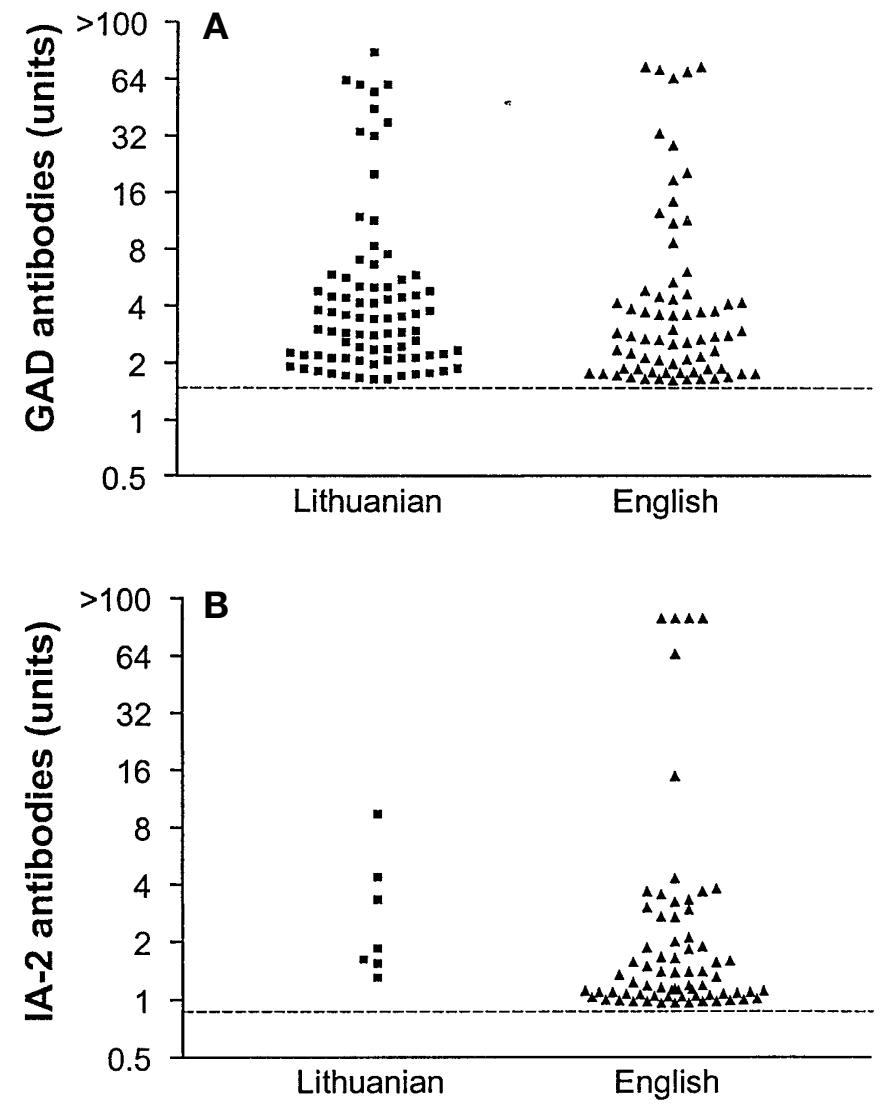

Fig. 1. A GAD antibody levels in samples from the 81 of 3053 Lithuanian and 70 of 2860 English schoolchildren with antibody levels $\geq 97.5^{\text {th }}$ centile of the English schoolchildren (dotted line). B IA-2 antibody levels in samples from the 7 of 3053 Lithuanian and 70 of 2860 English schoolchildren with antibody levels $\geq 97.5^{\text {th }}$ centile of the English schoolchildren (dotted line)

ple, small differences in assay sensitivity could drastically alter the number of subjects classed as "positive". Autoantibodies to the islet antigens glutamic acid decarboxylase (GAD) and the protein tyrosine phosphatase IA-2 (IA-2) offer an attractive alternative to ICA because they have similar disease sensitivity when used in combination $[9,10]$ and can be measured using well-standardized radiobinding assays.

For this reason, we compared the prevalence of subclinical islet autoimmunity in two cohorts of children from populations with differing incidences of Type I diabetes by measuring the levels of autoantibodies to GAD and IA-2 measured in the same laboratory over a 3-year period. One group of children came from Lithuania, with a mean incidence of 7.1 in 100000 a year between 1983 and 1992 [11-14]. Results from this cohort were compared with those in schoolchildren from the Oxford region of the UK, where a population-based register of childhood diabetes has been running since 1985 [15] showing an annual incidence of diabetes in children aged $0-14$ years of 17.1 in 100000 between 1985 and 1992. The incidence of childhood diabetes therefore differs by a factor of 2-3 in the two regions. We present the findings from this comparative survey and an analysis of the difficulties that must be surmounted before autoantibody prevalence can be accurately compared in groups from different populations.

\section{Subjects and methods}

Antibodies to GAD and IA-2 were measured in sera collected under non-fasting conditions during 1994 to 1998 from 3053 non-diabetic schoolchildren living in the Kaunas region of Lithuania. The median age of the children was 11.7 years, range 5.5-15 years and 1449 were boys. All samples were stored at $-20^{\circ} \mathrm{C}$ until analysis. These were compared with the results in samples collected and stored according to the same protocol from 2860 non-diabetic schoolchildren (median age 11.4 years, range $9.0-13.8$ years and 1488 boys) resident in the Oxford region of the United Kingdom [16]. Samples found to have levels of either antibody above the $97.5^{\text {th }}$ centile of the English schoolchildren were also tested for islet cell antibodies and insulin autoantibodies (IAA). Blood glucose concentrations were tested in the Lithuanian children by a glucose oxidase/peroxidase method using a reflectance meter (Reflolux SF, Boehringer-Mannheim, Germany) and plasma glucose was measured in the English children by the hexokinase/glucose-6-dehydrogenase method using an autoanalyser (CPA biochemical analyser, Coulter Electronics, Hialeah, Fl., USA). No children were found to have diabetes, i.e. none had blood glucose concentrations of $10.0 \mathrm{mmol} / \mathrm{l}$ or more.

$G A D$ and IA-2 antibodies. Antibodies to in vitro translated $\left[{ }^{35} \mathrm{~S}\right]-\mathrm{GAD}_{65}$ and $\left[{ }^{35} \mathrm{~S}\right]-\mathrm{PTP}-\mathrm{IA}-2_{\text {ic }}$ were measured by immunoassay as described previously [16]. Immune complexes were isolated on Protein A Sepharose (Pharmacia, Biotech AB, Uppsala, Sweden). After washing, bound counts per min were expressed as arbitrary units derived from a standard curve constructed using a positive serum with an arbitrary value of 100 units tested in each assay undiluted and diluted 1/2, $1 / 4,1 / 8,1 / 16,1 / 32,1 / 64$ and 1/128. Values above 100 units were beyond the steepest gradient of the standard curve and were reported as above 100 units. The same preparations of plasmid DNA were used for synthesising the $\left[{ }^{35} \mathrm{~S}\right]-\mathrm{GAD}_{65}$ and ${ }^{35}$ S]-PTP-IA- ${ }_{\text {ic }}$ labels throughout the study. The GAD antibody assay achieved $91 \%$ sensitivity with $99 \%$ specificity and the IA-2 antibody assay $74.4 \%$ sensitivity with $99 \%$ specificity in the First Immunology of Diabetes Society (IDS) Combined Antibody Workshop [17].

Islet cell antibodies. Islet cell antibodies were measured in undiluted sera by indirect immunofluorescence as described previously [18]. End-point titres of test samples were converted to Juvenile Diabetes Foundation (JDF) units by comparison with a standard curve of $\log _{2}$ JDF units compared with $\log _{2}$ of end-point titre of the standard sera. The threshold of detection was 4 JDF units. The assay achieved $81 \%$ sensitivity with $86 \%$ specificity in the First IDS Combined Antibody Workshop [17].

Insulin autoantibodies. Antibodies to ${ }^{125}$ I-labelled insulin were measured as described previously, using a format similar to that used to measure GAD and IA-2 antibodies [19]. Immune complexes were isolated with Protein A Sepharose (Pharma- 
Table 1. The prevalence of antibodies above the $97.5^{\text {th }}$ centile in English and Lithuanian schoolchildren

\begin{tabular}{lcr}
\hline Antibody combination & $\begin{array}{l}\text { English schoolchildren } \\
(n=2860)\end{array}$ & $\begin{array}{l}\text { Lithuanian schoolchildren } \\
(n=3053)\end{array}$ \\
\hline GAD antibodies & $70[2.4 \%(1.9-3.1)]$ & $81[2.7 \%(2.1-3.3)]$ \\
IA-2 antibodies & $70[2.4 \%(1.9-3.1)]$ & $7[0.2 \%(0.1-0.5)]$ \\
GAD and/or IA-2 antibodies & $133[4.7 \%(3.9-5.5)]$ & $88[2.9 \%(2.3-3.6)]$ \\
GAD and IA-2 antibodies & $7[0.2 \%(0.1-0.6)]$ & $0[0 \%(0-0.2 \%)]$ \\
GAD and/or IA-2 antibodies plus ICA & $10[0.3 \%(0.2-0.7)]$ & $17[0.6 \%(0.4-1.0)]$ \\
GAD and/or IA-2 antibodies plus IAA & $11[0.4 \%(0.2-0.7)]$ & $8[0.3 \%(0.1-0.6)]$ \\
Two or more markers & $17[0.6 \%(0.4-1.0)]$ & $22[0.7 \%(0.5-1.1)]$ \\
\hline
\end{tabular}

Data are given as $n$ [\% (95\% confidence interval)]

cia). Bound counts for each sample were calculated after subtraction of background counts and results were expressed in arbitrary units derived from a standard curve constructed from nine doubling dilutions of serum from a patient with longstanding Type I diabetes in normal human serum, spanning the range 0.39 units to 100 units. Sera with insulin binding above 0.4 units were tested in a competition assay in which further duplicate wells of each sample were incubated with label in the presence of excess unlabelled insulin (Humulin, Lilly, Basingstoke, UK). Specific bound counts were calculated for each sample by subtracting the counts of the tubes with excess unlabelled insulin from those with label alone and converted into arbitrary units as described above, including an additional standard at 0.2 units. The inter-assay coefficient of variation of the screening assay was $17 \%$ at 0.5 units and $13 \%$ at 1.4 units and of the competition assay was $31 \%$ at 0.6 units and $16 \%$ at 1.4 units. The assay achieved $58 \%$ sensitivity with $99 \%$ specificity on the samples included in the First IDS Combined Antibody Workshop [17].

Quality control. Quality control (QC) schemes for the IA-2, GAD and insulin autoantibody assays were in operation throughout the period during which the samples were analysed. For each marker, four sera with different levels of antibodies (negative, low, medium and high) were included on every plate. The sera were obtained from patients with Type I diabetes, ICA positive first-degree relatives of patients with Type I diabetes and healthy volunteers. The same sera were used as quality control samples for the GAD antibody assay throughout the measurement of samples from both the Oxford and Lithuanian cohorts. Over the time during which samples from the two cohorts were assayed for IA-2 antibodies, a single serum sample was used as a low quality control and samples from different bleeds from the same subject were used as negative, medium and high quality control sera. Results for each plate were accepted if the control values were within two standard deviations of the established mean. When necessary, new standard or control sera, which were obtained from the same subjects, were tested in parallel with the old batch at least ten times, to derive new values.

Statistical analysis. Antibody prevalences were expressed in relation to the centiles derived from the Oxford schoolchild cohort. Proportions were compared using chi-squared testing and distributions of autoantibody levels in the quality control sera were compared using the non-parametric Mann-Whitney $\mathrm{U}$ test. When necessary, significance levels were corrected $\left(p_{\text {corr }}\right)$ for the number of comparisons. The $95 \%$ confidence intervals were obtained using the exact probabilities of the Binomial distribution (Geigy Scientific tables). Statistical significance was defined as $p$ less than 0.05 .

\section{Results}

The $97.5^{\text {th }}$ centile for IA-2 and GAD antibodies in the Oxford schoolchildren corresponded to 0.94 units and 1.6 units, respectively. These thresholds gave sensitivities of 75 and $81 \%$ in 256 children with newly diagnosed Type I diabetes [16]. The distribution of combinations of antibody levels above these thresholds in English and Lithuanian schoolchildren is given in Table 1.

The prevalence of GAD antibodies above the 97. th $^{\text {th }}$ centile was similar in the Lithuanian and English schoolchildren $\left[\begin{array}{lll}2.7 \% & (2.1-3.3)\end{array}\right]$ vs $2.4 \%$ (1.9-3.1), $p_{\text {corr }}=$ NS] but the prevalence of IA-2 antibodies was much lower in the Lithuanian schoolchildren [0.2\% (0.1-0.5) vs $\left.2.4 \%(1.9-3.1), p_{\text {corr }}<0.001\right]$. Samples from seven Oxford schoolchildren $[0.24 \%$ $(0.1-0.6)]$ but no Lithuanian schoolchildren [0\% $(0-0.2)$ ] had both IA-2 and GAD antibody levels above the $97.5^{\text {th }}$ centile.

The 97. $5^{\text {th }}$ centile for ICA and IAA corresponded to 5 JDF units and 0.2 units respectively. Of the Oxford schoolchildren ten $[0.35 \%(0.2-0.7)]$ had IA-2 or GAD antibodies with ICA above the $97.5^{\text {th }}$ centile and eleven $[0.38 \%(0.2-0.7)]$ had IA-2 or GAD antibodies with IAA above the $97.5^{\text {th }}$ centile. Of the Lithuanian schoolchildren 17 [0.56\% (0.4-1.0)] with either IA-2 or GAD antibodies also had ICA and eight $[0.26 \%(0.1-0.6)]$ with GAD antibodies also had IAA above the $97.5^{\text {th }}$ centile. Overall, 17 Oxford schoolchildren [0.59\%(0.4-1.0)] and 22 Lithuanian schoolchildren $[0.72 \%(0.5-1.1)]$ had more than one antibody above the $97.5^{\text {th }}$ centile $\left(p_{\text {corr }}=\mathrm{NS}\right)$.

The results for the GAD and IA-2 autoantibody quality control material during the periods when the samples from the two schoolchild cohorts were assayed are shown in Table 2. The low and mid level GAD antibody control sera show small but significant increases between the two periods. The low IA2 antibody control serum, which was also common to both periods of measurement, did not show a statistically significant change in level during the study. Results of negative and high QC are not shown because they fell outside the range of the standard curve. 
Table 2. Results for GAD and IA-2 antibody quality control samples during periods when the English and Lithuanian schoolchild samples were assayed

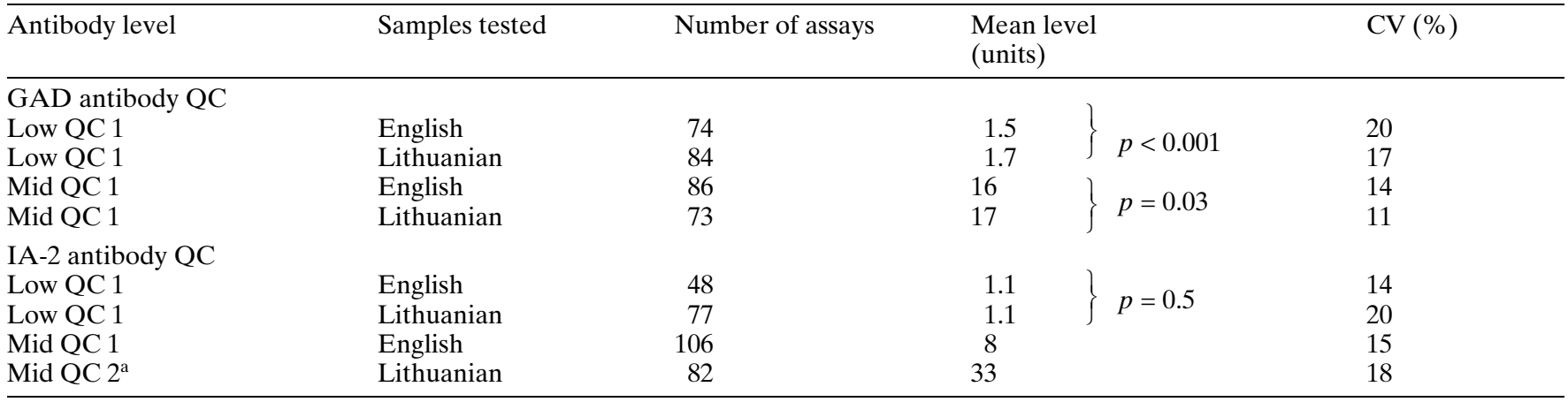

QC sera for each level were obtained from a single subject but the mid QC samples used in the IA-2 assays (QC 1 and QC2 $\left.{ }^{\mathrm{a}}\right)$ were collected on different dates three years apart

\section{Discussion}

Epidemiological analyses of possible environmental factors, for example by case control studies, use clinical diagnosis of diabetes as their end point. One limitation of this approach is that it will not detect non-diabetic children within the study cohort who have developed subclinical anti-islet autoimmunity and are at high risk of diabetes. These children who will become diabetic in future could however be identified with reasonable confidence by testing for multiple circulating islet autoantibodies [16, 20-21] because detection of two or more antibodies is associated with a high risk of progression to diabetes, whereas subjects with a single islet autoantibody seem to be at low risk even after 20 years [22]. Studies into the environmental causes of Type I diabetes should therefore ideally be supplemented by autoantibody estimation within the background population [23]. Because there are major differences in the frequency of childhood diabetes across Europe [1], comparison of the distribution of humoral islet autoimmunity in cohorts from different populations is a logical step towards validating this approach.

We set out to do a stringent comparison of islet antibody prevalences between two cohorts from European populations with a widely different incidence of Type I diabetes (17.1 vs 7.1 cases in 100000 a year) over the same time period. Samples were collected from schoolchildren recruited using the identical protocol, overt diabetes was excluded by blood glucose estimation and antibody levels were measured in well-standardised assays done in a single laboratory. The two-step screening procedure used for this study has been shown to achieve high sensitivity and specificity for Type I diabetes in cohorts from several populations $[16,20-21]$.

We found that the prevalence of GAD antibodies was similar in the Lithuanian and English schoolchildren $(2.7$ vs $2.4 \%)$ but that the prevalence of IA-2 antibodies was much lower in the Lithuanian cohort ( 0.2 vs $2.4 \%)$. This difference could be due to genetic differences between the background populations because IA-2 antibodies are associated with HLA DR4 haplotypes in newly diagnosed patients and their relatives [24-26]. The frequency of HLA haplotypes in Lithuania is not known. The tenfold difference between our two cohorts in the prevalence of IA-2 antibodies should however be examined critically in the light of the possibility that, despite our precautions, assay variation might be responsible. The real point at issue is how to distinguish reliably between true difference and assay variation in this and future studies.

The major difference in distribution of IA-2 antibodies in the two cohorts occurred around the threshold of positivity and the prevalence of high levels of antibodies was more comparable in the two groups. Precise measurement of low autoantibody levels is a generic difficulty for all laboratories, and is amplified when testing low risk groups. This is because results of even the best test will include a proportion of 'spurious' signals amongst the 'true' signals and the proportion of false signals increases as the overall risk of disease in the group falls. Some of these 'spurious' results will relate to assay precision in the broadest sense, including the variability of the assay, as well as potential problems occurring in sample handling, labelling etc. Others will be related to factors in the sample such as high levels of IgG or other autoantibodies interfering with the assay [27]. In our study similar results were obtained for the low quality control samples during the measurement of samples from both cohorts. This implies that no assay drift occurred. Therefore any assay-related differences which might have contributed to the differing results in the two cohorts would have been due to variations in the frequency of random errors between the testing periods, which were not detectable with our quality control procedures.

How can this uncertainty be reduced in future studies? Ideally, antibodies in both populations should have been assayed concurrently, then errors would have contributed evenly to the background 
prevalence in both cohorts. Circumstances often dictate measurement at different times, however, and we must therefore rely on quality control schemes to identify changes in assay performance. Quality control of assays used for screening low risk groups has proved particularly difficult [28-29] and, although our scheme was designed to cover the whole range of interest, it was biased towards avoiding 'false negative' results to ensure maximum sensitivity. The majority of spurious results related to assay precision would be eliminated simply by repeating the test. For example, of 70 English schoolchildren only 30 had IA-2 antibody levels above the threshold of positivity confirmed on re-testing but 7 of 7 Lithuanian children had IA-2 antibodies above the threshold in both initial and repeat assays. There remained however, a significant difference in the prevalence of IA- 2 antibodies in the two cohorts $[1.0 \%$ (95\% CI $0.7-1.6 \%)$ vs $0.2 \%(95 \%$ CI $\left.0.1-0.5), p_{\text {corr }}<0.001\right]$. Increased specificity could also be achieved by retesting of samples collected at multiple time-points from the same subject. A further technical improvement would be to include 'external' blinded quality control sera in the screening process, a procedure we would advocate for similar studies in the future.

The problems intrinsic to measurement of a single antibody on a single occasion, and near the threshold of detection, are largely eliminated by using a second disease-associated test, e.g. another islet autoantibody. This is a reliable way to identify "true positives" and partly accounts for the power of prediction based on combinations of antibody markers in family members [3-4] and the general population [16, 20-21]. We can therefore feel confident, on the basis of multiple antibody positivity, that the prevalence of children at high risk of progression to diabetes is similar in the two population samples.

A carefully planned comparison of the prevalence of autoantibody levels in a cohort of English and one of Lithuanian schoolchildren found a similar prevalence of multiple antibodies - indicative of a high risk of progression - despite a lower incidence of Type I diabetes in Lithuania. If confirmed, these results suggest that a rapid increase in the incidence of Type I diabetes in Lithuania is to be expected, consistent with the rapid rise in incidence reported from Central and Eastern Europe [30].

Acknowledgements. We are grateful to E. Brazaitiene and $\mathrm{N}$. Grigiene for help with sample collection, and to W. Moore and S. Wrage for technical support. This study was done within the framework of the EURODIAB ACE and EURODIAB TIGER EU concerted actions. The Bart's-Oxford study is supported by the British Diabetic Association. PJB was funded by a JDFI Career Development Award.

\section{References}

1. Green A, Gale EA, Patterson CC for the EURODIAB ACE study (1992) Incidence of childhood-onset insulin-dependent diabetes mellitus: the EURODIAB ACE study. Lancet 339: 905-909

2. Gorsuch AN, Spencer KM, Lister J et al. (1981) The natural history of type I (insulin-dependent) diabetes mellitus: evidence for a long prediabetic period. Lancet ii: 1363-1365

3. Bingley PJ, Christie MR, Bonifacio E et al. (1994) Combined analysis of autoantibodies improves prediction of IDDM in islet-cell antibody positive relatives. Diabetes 43: 1304-1310

4. Verge CF, Gianani R, Kawasaki E et al. (1996) Prediction of type 1 diabetes in first-degree relatives using a combination of insulin, GAD, and ICA512bdc/IA-2 autoantibodies. Diabetes 45: 926-933

5. Boehm BO, Manfras B, Seissler J et al. (1991) Epidemiology and immunogenetic background of islet cell antibodypositive nondiabetic schoolchildren. Ulm-Frankfurt population study. Diabetes 40: 1435-1439

6. Levy-Marchal C, Tichet J, Fajardy I, Gu XF, Dubois F, Czernichow P (1992) Islet cell antibodies in normal French schoolchildren. Diabetologia 35: 577-582

7. Bingley PJ, Bonifacio E, Shattock M et al. (1993) Can islet cell antibodies predict IDDM in the general population? Diabetes Care 16: 45-50

8. Adojan B, Knip M, Vahasalo P et al. (1996) Relationship between the incidence of childhood IDDM and the frequency of ICA positivity in nondiabetic children in the general population. Diabetes Care 19: 1452-1454

9. Bonifacio E, Genovese S, Braghi S et al. (1995) Islet autoantibody markers in IDDM: risk assessment strategies yielding high sensitivity. Diabetologia 38: 816-822

10. Wiest-Ladenberger U, Hartmann R, Hartmann U, Berling K, Böhm BO, Richter W (1997) Combined analysis and single-step detection of GAD65 and IA2 autoantibodies in IDDM can replace the histochemical islet cell antibody test. Diabetes 46: 565-571

11. Grabauskas V, Urbonaite B, Padaiga Z (1991) Incidence of childhood insulin-dependent diabetes mellitus in Lithuania 1983-1988. Acta Paediatr Scand 80: 718-719

12. Urbonaitè B, Padaiga Ž, Žalinkevičius R et al. (1995) Incidence trends and seasonality patterns of childhood onset IDDM in Lithuania during 1983-1992. Acta Medica Lituanica 3: 25-33

13. Urbonaite B, Padaiga Ž, Marčiulionytė D et al. (1996) Childhood onset diabetes register in Lithuania: Prevalence rates during 1983-1994 and register's utilisation for practical health care. Acta Medica Lituanica 4: 83-86

14. Padaiga Z, Tuomilehto J, Karnoven M et al. (1997) Incidence trends in childhood onset IDDM in four countries around the Baltic sea during 1983-1992. Diabetologia 40: 187-192

15. Gardner SG, Bingley PJ, Sawtell PA et al. (1997) Rising incidence of insulin dependent diabetes in children under 5 years in the Oxford region: time trend analysis. BMJ 315: 713-717

16. Bingley PJ, Bonifacio E, Williams AJ, Genovese S, Bottazzo GF, Gale EAM (1997) Prediction of IDDM in the general population: Strategies based on combinations of autoantibody markers. Diabetes 46: 1701-1710

17. Verge CF, Stenger D, Bonifacio E et al. (1998) Combined use of autoantibodies (IA-2 autoantibody, GAD autoantibody, insulin autoantibody, cytoplasmic islet cell antibodies) in type 1 diabetes: combinatorial islet autoantibody workshop. Diabetes 47: 1857-1866 
18. Bonifacio E, Bingley PJ, Shattock M et al. (1990) Quantification of islet-cell antibodies and prediction of insulindependent diabetes. Lancet 335: 147-149

19. Williams AJ, Bingley PJ, Bonifacio E, Palmer JP, Gale EA (1997) A novel micro-assay for insulin autoantibodies. J Autoimmun 10: 473-478

20. Hagopian WA, Sanjeevi CB, Kockum I et al. (1995) Glutamate Decarboxylase-, Insulin-, and Islet Cell-Antibodies and HLA typing to detect diabetes in a general population-based study of Swedish children. J Clin Invest 95: 1505-1511

21. Strebelow M, Schlosser M, Ziegler B, Rjasanowski I, Ziegler M (1999) Karlsburg Type 1 diabetes risk study of a general population: frequencies and interactions of the four major Type 1 diabetes-associated autoantibodies studied in 9419 schoolchildren. Diabetologia 42: 661-670

22. Gardner SG, Gale EA, Williams AJ et al. (1999) Progression to diabetes in relatives with islet autoantibodies: is it inevitable? Diabetes Care 22: 2049-2054

23. Harrison LC (1996) Cow's milk and IDDM. Lancet 348: 905-906
24. Genovese S, Bonfanti R, Bazzigaluppi E (1996) Association of IA-2 autoantibodies with HLA DR4 phenotypes in IDDM. Diabetologia 39: 1223-1226

25. Vandewalle CL, Falorni A, Lernmark A et al. (1997) Associations of GAD65- and IA-2- autoantibodies with genetic risk markers in new-onset IDDM patients and their siblings. Diabetes Care 20: 1547-1552

26. Sanjeevi CB, Hagopian WA, Landin-Olsson M et al. (1998) Association between autoantibody markers and subtypes of DR4 and DR4-DQ in Swedish children with insulindependent diabetes reveals closer association of tyrosine phosphatase autoimmunity with DR4 than DQ8. Tissue Antigens 51: 281-286

27. Bingley PJ, Bonifacio E, Gale EA (1999) Predicting type 1 diabetes. In Marshall SM, Home P, Rizza R (eds) Diabetes Annual/12, Elsevier, Amsterdam, pp 1-20

28. Smith A, Elkind A, Eardley A (1989) Making cervical screening work. BMJ 298: 1662-1664

29. Muir Gray JA, Austoker J (1998) Quality assurance in screening programmes. Br Med Bull 54: 983-992

30. EURODIAB ACE Study Group (2000) Wide variability and increasing incidence of childhood diabetes in Europe. Lancet 355: 873-876 